\title{
Compliance with and accuracy of daily self-assessment of peak expiratory flows (PEF) in asthmatic subjects over a three month period
}

\author{
P. Verschelden, A. Cartier, J. L'Archevêque, C. Trudeau, J-L. Malo
}

Compliance with and accuracy of daily self-assessment of peak expiratory flows (PEF) in asthmatic subjects over a three month period. P. Verschelden, A. Cartier, J. L'Archevêque, C. Trudeau, J-L. Malo. @eERS Journals Ltd 1996.

ABSTRACT: Serial peak expiratory flow (PEF) assessment has been proposed in the clinical evaluation of asthma. In subjects attending the asthma clinic of a tertiary care hospital, we wanted to assess: 1) compliance in performing PEF; and 2) accuracy of a PEF-diary.

Twenty adult asthmatic subjects, all using inhaled steroids, were asked to assess their PEF in the morning and evening with a VMX instrument (Clement Clarke Int., Colombus, OH, USA). This instrument, which incorporates a standard miniWright peak flow meter, stores PEF data on a computer chip. Subjects were not informed that the values were being stored.

The mean duration of PEF monitoring was 89 days (range 44-131 days). For the total of 20 subjects, it was estimated that 3,482 values should have been written down and stored on the VMX computer chip. Whilst 1,897 values $(54 \%)$ were written down, only 1,533 (44\%) were stored, 425 values being invented. Morning and evening values were stored on $34 \%$ of days; and values were stored at least once a day on $55 \%$ of days. The values written down corresponded precisely to stored values $90 \%$ of the time, and were within $\pm 20 \mathrm{~L} 94 \%$ of the time.

We conclude that: 1) compliance with daily peak expiratory flow assessments is generally poor in chronic stable asthmatic subjects assessed on two visits separated by a 3 month period; and 2 ) a substantial percentage of values $(22 \%)$ is invented.

The unsatisfactory compliance with peak expiratory flow monitoring in this group of asthmatics on inhaled steroids underlines the need for similar studies on peak expiratory flow monitoring as part of an action treatment plan, and in more severe and brittle asthmatics.

Eur Respir J., 1996, 9, 880-885.
Dept of Chest Medicine, Hôpital du SacréCoeur, Montreal, Canada, J-L. Malo is a research scholar with the Fonds de la Recherche en Santé du Quebéc and the Université de Montréal School of Medicine.

Correspondence: J-L. Malo

Dept of Chest Medicine

Hôpital du Sacré-Coeur

5400 West Gouin

Montreal

Canada H4J $1 \mathrm{C} 5$

Keywords: Asthma

peak expiratory flow rate

subject compliance

Received: October 271995

Accepted after revision January 311996

This study was partly funded by the Centre québécois d'excellence en santé respiratoire.
Asthma is defined as a disease "characterized by an increased responsiveness of the trachea and bronchi to various stimuli and manifested by a widespread narrowing of the airways that changes in severity either spontaneously or as a result of therapy" [1]. The asthmatic subject has a fluctuating symptomatology as well as a varying degree of obstruction (and/or hyperresponsiveness). Spirometry, physical examination and peak expiratory flow (PEF) measurements, and recorded diary of PEF values or symptoms are currently the most widely used means of assessment of this condition. Physical examination by a trained physician is not superior to the subject's own perception of symptoms with regards to the degree of airways obstruction as determined by PEF measurements [2]. The subject's perception of symptoms does have its limits. Rubinfeld and PAINE [3] demonstrated that airway resistance had to increase substantially before symptoms appears, and that $15 \%$ of subjects were unable to sense the presence of marked obstruction. Several authors have also found that the presence and intensity of symptoms in certain subjects did not satisfactorily correlate with the degree of airway obstruction $[4,5]$.

Serial PEF determination is currently considered a valuable tool for monitoring asthma and detecting exacerbation, and it has been advocated in asthma management plans $[6,7]$. However, satisfactory data concerning its advantages and inconveniences is lacking. One advantage is that this method of monitoring makes use of instruments that are portable and inexpensive. PEF is also easy to perform. However, monitoring is impeded in illiterate subjects. Compliance with and accuracy of readings have not been evaluated. In subjects investigated for occupational asthma, it was found that approximately $50 \%$ of written values did not correspond with stored values $[8,9]$. It is unknown whether these results can be extrapolated to subjects with chronic asthma for whom no financial benefit, in terms of compensation, is expected.

We studied compliance with and accuracy of PEF monitoring in 20 asthmatic subjects. Each subject was seen 
on two occasions, separated by approximately 3 months, at the specialized asthma clinic of a tertiary care hospital. Factors that can affect these variables were examined. Our hypothesis was that compliance would be unsatisfactory, and would decrease proportionately as the duration of monitoring increased.

\section{Material and methods}

\section{Subjects}

Twenty adult asthmatic subjects were consecutively recruited by the two attending physicians at the asthma clinic of a tertiary care hospital (JLM and AC). Half of the subjects were new referrals and the other half had been attending the clinic regularly. The subjects satisfied the criteria for asthma set forth by the American Thoracic Society (ATS) [1], and all had required inhaled steroids regularly during the 3 months or more preceding the initial visit. They underwent spirometry [10] and skin-prick tests with a battery of 15 common inhalants. All were in a clinically steady-state, defined as the absence of nocturnal awakenings due to asthma and no abuse of inhaled beta $_{2}$-adrenergic agent.

\section{Methods}

Subjects were first informed of the importance of PEF monitoring to the management of their asthmatic condition but without specific instructions on how to adjust their treatment according to their values. They were then given a portable PEF instrument and shown how to assess PEF in the morning upon awakening and at night before going to bed. Subjects were told not to use any other peak flow meter. They were to report by writing in their diary the date, indicating a.m. or p.m. and the value obtained. They were told to bring their diary to the following visit and were given the date of this next appointment.

A VMX instrument (Clement Clark, Inc., Columbus, OH, USA) was used, that consists of a standard miniWright peak flow meter equipped with a computer chip memory that can store up to 400 values. The subjects were taught how to use the instrument. After setting the marker at zero, they were to turn on the VMX and then perform a maximal expiratory effort and repeat this manoeuvre three times. The best PEF value obtained appeared on a digital screen, and they were told to write it down with the date and time of day (morning or evening) at which it was recorded. The signal generated by the standard mini-Wright peak flow meter is digitized, processed and memorized by an on-board computer along with the date and time. The VMX computer chip records the best of three values. The absence of a blow cannot generate a signal that could be wrongly stored. The VMX has a computer connection to transfer the data to a personal computer. At the end of each subject's study period, the stored data for that subject were collected and analysed.

Unpublished data obtained in our laboratory in $48 \mathrm{sub}$ jects with asthma and a wide range of PEF values (uniform PEF distribution ranging 150-700 L.min ${ }^{-1}$ ) showed good reproducibility in PEF values assessed by: 1) the standard mini-Wright peak flow meter and the VMX stored value $\left(\mathrm{r}^{2} 0.94 ;\right.$ mean \pm SD difference $\left.=5 \pm 32 \mathrm{~L} \cdot \mathrm{min}^{-1}\right)$; 2) the standard mini-Wright peak flow meter and VMX written values $\left(\mathrm{r}^{2} 0.96\right.$; mean $\pm \mathrm{SD}$ difference $=3.3 \pm 26$ $\left.\mathrm{L} \cdot \mathrm{min}^{-1}\right)$; and 3 ) the VMX stored and digitalized values $\left(\mathrm{r}^{2} 0.97\right.$; mean $\pm \mathrm{SD}$ difference $\left.=1.5 \pm 24 \mathrm{~L} \cdot \mathrm{min}^{-1}\right)$.

The protocol was accepted by a Local Ethics Committee, with the specification that subjects with poor compliance should not be blamed.

\section{Analysis of results}

Compliance was defined as the subject's consistent measurement of his/her PEF twice daily or at least once a day, and the transcription of the values obtained in the diary provided. This compliance was measurement objectively by comparing the computer-stored value with the diary-reported value. Three situations could arise: 1) a diary value that corresponded to the VMX stored value with respect to the date, and the indication of a.m. or p.m. was interpreted as an indication that the subject had been "compliant"; 2) a diary value with no corresponding VMX-stored value was considered to be an invented value; and 3) a VMX-stored value without a corresponding diary value was a failure in transcription. The percentage of compliance was calculated from (number of stored values/expected number of values $) \times 100$.

The accuracy of results was examined by comparing the diary reported values with VMX stored values. The ratio: ((Highest PEF reading - lowest PEF reading)/mean value $) \times 100$ was used as a measure of the fluctuation of asthma during study period. Reference values for forced expiratory value in one second (FEV1) and PEF were obtained from KNUDSON et al. [11]. The analysis of the influence of variables (sex, age, duration of asthma, baseline FEV1, socioeconomic status) on compliance, was carried out by regression analysis and unpaired t-test. A p-value of less than 0.05 was considered significant.

\section{Results}

Table 1 summarizes the baseline anthropometric, clinical and functional results. The majority of subjects were atopic, and all but one had had asthma diagnosed at least 5 yrs previously. All were using inhaled steroids. The mean duration of PEF assessment was close to 3 months. Twelve subjects had significant bronchial obstruction with a FEV1 value $<80 \%$ predicted. Nine of these also had a significantly reduced FEV1/forced vital capacity (FVC) ratio ( $<70 \%$ pred). As shown in table 2 , all but two subjects had a variability in PEF within the $95 \%$ confidence interval $(95 \% \mathrm{CI})$ range that has been described in asthmatic subjects [11].

For the total group of 20 subjects, it was estimated that 3,482 values should have been written down in the diaries, and the same number stored in the VMX computer chips. In fact, a total of 1,533 values (44\%) were stored in the VMX. Twice daily assessment with corresponding stored data was found in $34 \%$ of the days. Assessment occurred at least once a day for $55 \%$ of days. PEF assessment was carried out on $49 \%$ of mornings and $46 \%$ of evenings. Table 2 shows the individual 
Table 1. - Baseline anthropometric, clinical and functional results

\begin{tabular}{|c|c|c|c|c|c|c|c|c|c|c|c|c|}
\hline $\begin{array}{l}\text { Subj. } \\
\text { No. }\end{array}$ & Sex & $\begin{array}{l}\text { Age } \\
\text { yrs }\end{array}$ & Atopy\# & $\begin{array}{c}\text { Asthma } \\
\text { duration } \\
\text { yrs }\end{array}$ & $\begin{array}{l}\text { Medication } \\
\mu \mathrm{g} \cdot \text { day }^{-1}\end{array}$ & $\begin{array}{l}\text { Smoking } \\
\text { history }\end{array}$ & $\begin{array}{l}\text { Academic } \\
\text { level }\end{array}$ & $\begin{array}{l}\text { Assessment } \\
\text { duration } \\
\text { days }\end{array}$ & $\begin{array}{l}\text { FEV } 1 \\
\% \text { pred }\end{array}$ & $\begin{array}{c}\mathrm{FEV}_{1 / \mathrm{FVC}} \\
\%\end{array}$ & $\begin{array}{r}\mathrm{Pl} \\
\mathrm{L} \cdot \mathrm{min}^{-1}\end{array}$ & $\%$ pred \\
\hline 1 & M & 39 & + & 6 & 400 & ES & Sec & 85 & 72 & 56 & 563 & 109 \\
\hline 2 & $\mathrm{~F}$ & 48 & + & 29 & 2000 & NS & $\mathrm{Sec}$ & 85 & 75 & 70 & 393 & 107 \\
\hline 3 & F & 46 & - & 11 & 2000 & ES & Col-U & 93 & 66 & 56 & 307 & 83 \\
\hline 4 & M & 28 & + & 29 & 1000 & $\mathrm{~S}$ & Col-U & 105 & 82 & 65 & 531 & 98 \\
\hline 5 & $\mathrm{~F}$ & 23 & + & 9 & 600 & $\mathrm{~S}$ & Col-U & 69 & 91 & 88 & 412 & 111 \\
\hline 6 & F & 25 & + & 20 & 200 & NS & Col-U & 65 & 103 & 81 & 419 & 112 \\
\hline 7 & M & 34 & + & 6 & 500 & NS & Col-U & 56 & 74 & 67 & 542 & 90 \\
\hline 8 & M & 27 & + & 13 & 1000 & NS & $\mathrm{Sec}$ & 92 & 78 & 62 & 521 & 87 \\
\hline 9 & M & 34 & + & 14 & 800 & NS & $\mathrm{Sec}$ & 93 & 27 & 71 & 266 & 53 \\
\hline 10 & $\mathrm{~F}$ & 39 & + & 25 & 400 & NS & Col-U & 104 & 100 & 79 & 446 & 117 \\
\hline 11 & F & 49 & - & 10 & 400 & NS & Col-U & 44 & 46 & 64 & 238 & 61 \\
\hline 12 & $\mathrm{~F}$ & 60 & + & 10 & 2000 & NS & Prim & 64 & 57 & 69 & 274 & 81 \\
\hline 13 & M & 51 & + & 1 & 800 & ES & Col-U & 131 & 91 & 73 & 542 & 101 \\
\hline 14 & M & 54 & ND & 15 & 1600 & $\mathrm{~S}$ & UK & 86 & 34 & 33 & 155 & 46 \\
\hline 15 & M & 38 & + & 20 & 2000 & ES & Sec & 93 & 76 & 75 & 308 & 53 \\
\hline 16 & $\mathrm{~F}$ & 29 & + & 24 & 800 & NS & $\mathrm{Sec}$ & 94 & 90 & 89 & 433 & 109 \\
\hline 17 & $\mathrm{~F}$ & 45 & + & 10 & 1600 & NS & $\mathrm{Sec}$ & 101 & 96 & 73 & 226 & 63 \\
\hline 18 & $\mathrm{~F}$ & 59 & - & 25 & 1000 & ES & $\mathrm{Sec}$ & 90 & 68 & 65 & 250 & 76 \\
\hline 19 & M & 49 & + & 5 & 1000 & $\mathrm{~S}$ & $\mathrm{Sec}$ & 105 & 72 & 58 & 562 & 110 \\
\hline 20 & $\mathrm{~F}$ & 21 & + & 15 & 400 & NS & Col-U & 86 & 91 & 90 & 621 & 142 \\
\hline Mean & & 40 & & 15 & & & & 87 & 74 & 69 & 400 & 90 \\
\hline SD & & 12 & & 8 & & & & 20 & 21 & 13 & 136 & 25 \\
\hline
\end{tabular}

\#: Atopy, defined as at least one immediate skin reaction by the prick method to 15 common inhalants; ‡: Medication, beclomethasone daily dose; Subj.: subject; M: male; F: females; S: smoker; ES: ex-smoker; NS: nonsmoker; Prim: primary school; Sec: secondary level; Col-U: college-university level; UK: unknown; FEV1: forced expiratory volume in one second; FVC: forced vital capacity; PEF: peak expiratory flow; \% pred: percentage of predicted value; ND: not determined. See text for source of reference values for FEV1 and PEF. Listed functional values are those obtained on entry.

Table 2. - Variability of and compliance with PEF monitoring

\begin{tabular}{|c|c|c|c|c|c|}
\hline $\begin{array}{l}\text { Subj. } \\
\text { No. }\end{array}$ & $\begin{array}{c}\text { Variability* } \\
\%\end{array}$ & $\begin{array}{l}\text { Compliance } \\
\text { twice daily }\end{array}$ & $\begin{array}{r}\text { Compliance } \\
\text { once daily }\end{array}$ & $\begin{array}{c}\text { Invented values } \\
\%\end{array}$ & $\begin{array}{c}\text { Falsified values } \\
\%\end{array}$ \\
\hline 1 & 85 & 20 & 95 & 0 & 4 \\
\hline 2 & 101 & 40 & 64 & 8 & 1 \\
\hline 3 & 56 & 9 & 29 & 0 & 0 \\
\hline 4 & 40 & 19 & 49 & 39 & 18 \\
\hline 5 & 29 & 80 & 81 & 0 & 27 \\
\hline 6 & 29 & 5 & 23 & 0 & 0 \\
\hline 7 & 29 & 95 & 100 & 0 & 4 \\
\hline 8 & 52 & 1 & 12 & 0 & 0 \\
\hline 9 & 77 & 84 & 90 & 0 & 4 \\
\hline 10 & 38 & 35 & 66 & 4 & 8 \\
\hline 11 & 64 & 95 & 100 & 0 & 0 \\
\hline 12 & 93 & 88 & 100 & 5 & 3 \\
\hline 13 & 44 & 7 & 26 & 0 & 0 \\
\hline 14 & 87 & 16 & 40 & 6 & 17 \\
\hline 15 & 48 & 4 & 12 & 79 & 45 \\
\hline 16 & 25 & 4 & 24 & 73 & 0 \\
\hline 17 & 131 & 30 & 51 & 19 & 0 \\
\hline 18 & 121 & 82 & 100 & 0 & 1 \\
\hline 19 & 19 & 3 & 19 & 13 & 0 \\
\hline 20 & 37 & 6 & 22 & 0 & 0 \\
\hline Mean & 60 & 36 & 55 & 12 & 7 \\
\hline SD & 33 & 36 & 34 & 23 & 12 \\
\hline
\end{tabular}

*: expressed as: (maximum value - minimum value)/mean value) $\times 100$. Compliance is expressed as the percentage of values that were recorded at least twice daily (as requested) or at least once daily over the number of stored values. The invented values correspond to those values that were written down by the subject but not recorded in the VMX apparatus; whereas, the falsified values were those for which the written value did not correspond precisely to the stored value. Subj.: subject; PEF: peak expiratory flow. 
results for compliance. Only six subjects had a rate of compliance with the twice daily assessment greater than $80 \%$. Only 10 subjects had a rate of compliance $>50 \%$ when the criterion was reduced to at least a once daily value. It was calculated that 1,897 values were reported in the diaries. It was found that 425 (22\% or 425 out of 1,897) diary-reported data had no corresponding VMX stored value; these were considered to be invented values. As shown in table 2, more than $25 \%$ of values were invented in three subjects (Nos. 4, 15 and 16). Those subjects with the best compliance $(>50 \%, \mathrm{n}=6)$ were the same subjects who tended not to invent data, whereas those who were responsible for $93 \%$ of all invented data had a poor compliance $(<33 \%, \mathrm{n}=5)$. In two subjects (Nos. 5 and 15), stored values did not correspond to written values in more than $25 \%$ of instances, but, as a whole, the correspondence between written and stored values, when these were not invented, was very satisfactory. Subjects were $94 \%$ accurate in the reporting of values (within $20 \mathrm{~L} \cdot \mathrm{min}^{-1}$, such a difference being beyond the accepted reproducibility of the test [12]). Sixty one values among the stored data had no corresponding diaryreported value; these were considered as a test failure in transcribing the performed PEF.

Figure 1 illustrates the evolution of compliance over time. The best compliance was obtained during the first 2 weeks, with a progressive diminution thereafter and an increasing number of invented values. Three patterns of compliance could be determined: the subject with variable compliance; the subject with good compliance throughout the study period; and the rapidly poor complier (fig. 2). The correspondence between stored and falsified values is illustrated in figure 3 . While the number of stored values decreased with time, the number of invented increased, peaked at the fourth week and then diminished.

No significant correlation was found between compliance (at least once a day) on the one hand and any of the following: age $(\mathrm{r}=0.10)$, duration of asthma $(\mathrm{r}=0.09)$, initial FEV1 $(r=0.40)$ or PEF fluctuation $(r=0.43)$.

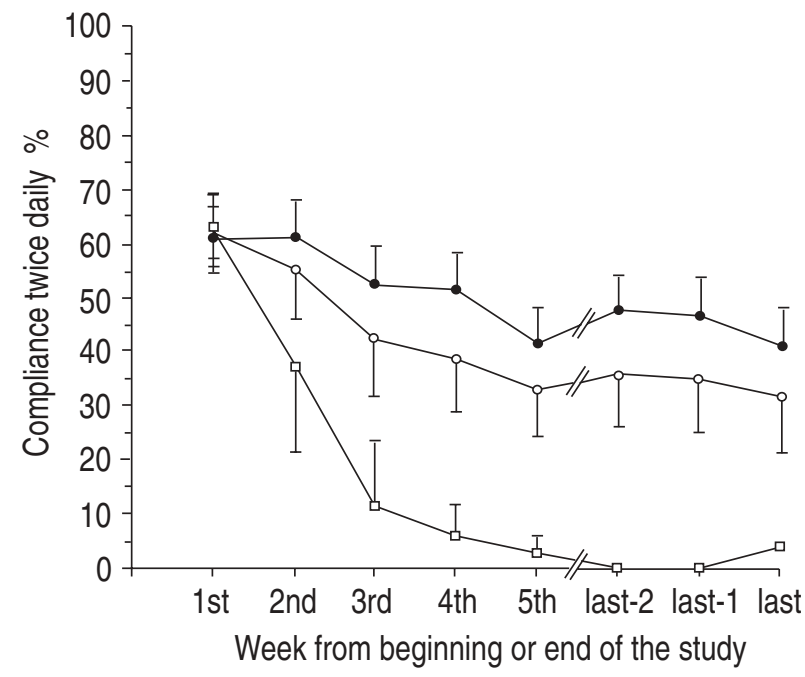

Fig. 1. - Evolution of compliance (at least twice daily) in all subjects and by separating "inventors" (the five subjects who invented more than $10 \%$ of results, i.e. Nos. 5, 15, 16, 17 and 19 of table 2) from those who were not inventors. Values are presented as mean and SEM. $\longrightarrow-$ : : all subjects $(n=20) ;-\square-$ : inventors $(n=5) ; \longrightarrow$ : noninventors.
Compliance did not different significantly between: males $(28 \pm 35 \%)$ and females (43 $\pm 37 \%)$; college or university academic level $(37 \pm 38 \%)$; those with a primary or secondary academic level $(36 \pm 36 \%)$; those who were newly referred to the clinic or had been seen at least once before.

a) Subject No. 14

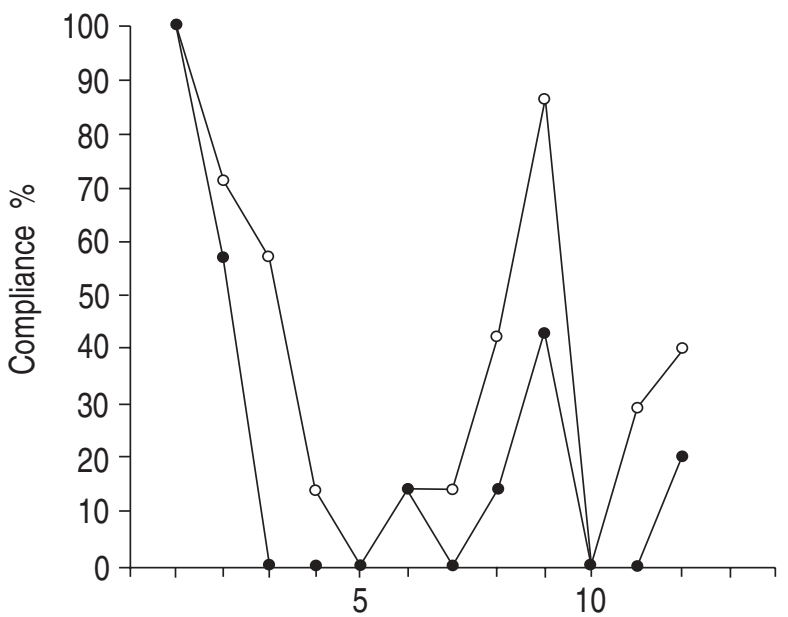

b) Subject No. 18

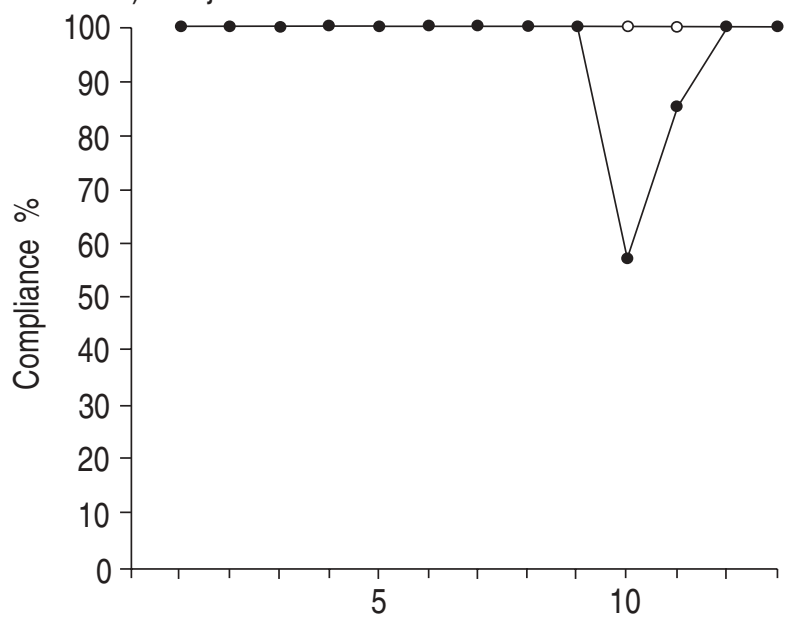

c) Subject No. 19

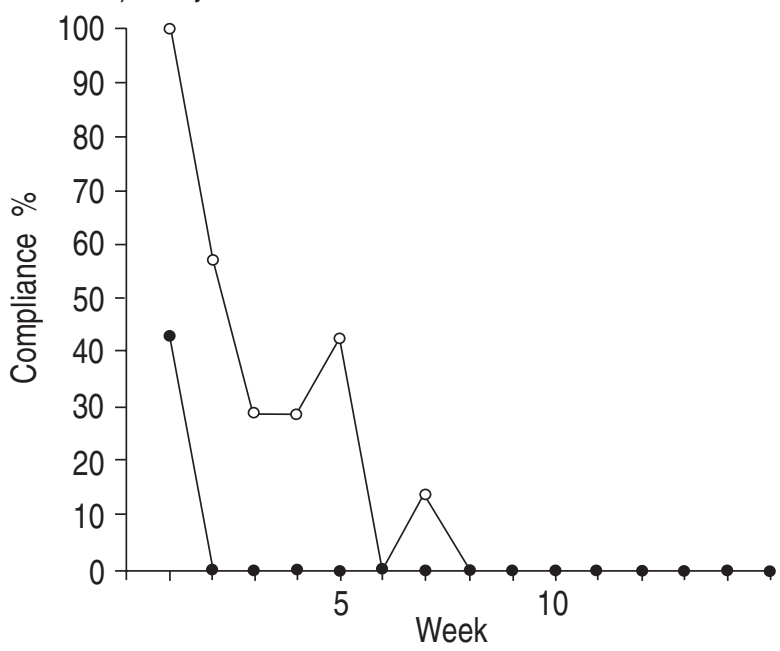

Fig. 2. - Examples of three patterns of compliance in three different subjects: a) "variable compliance"; b) "good compliance"; and c) "rapidly poor compliance". _—_ : at least once daily; ——: twice daily. 


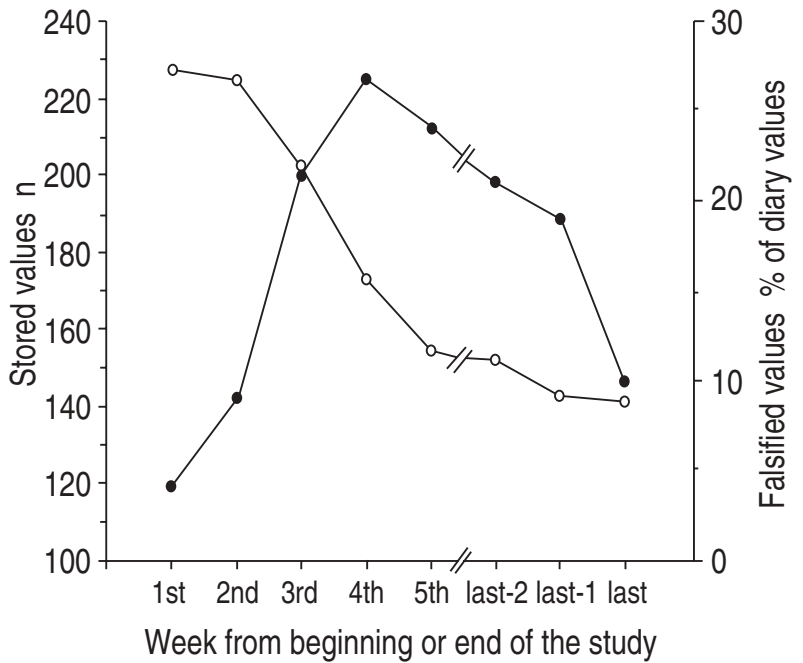

Fig 3. - Correspondence between stored and falsified values.-O- : stored values; —- : falsified values (\% of stored values).

\section{Discussion}

We found that compliance with instructions for selfmonitoring of PEF was low in asthmatic subjects who were asked to assess their values over a 3 month period, the explanation given to the patient being that this information will be useful for assessing the severity of asthma on their next appointment. This approach is similar to the situation of a clinical or a pharmacological trial in which the efficacy is usually assessed by a combination of diary and serial PEF measurement. However, this design is different from that which can be planned for other clinical purposes, in which it can be hypothesized that compliance would be improved: 1) firstly, in a situation of reinforcing the need for PEF monitoring and giving instructions on an action treatment plan based on PEF values; 2) secondly, asking subjects to record PEF whenever they feel their symptoms increase, therefore for short intervals instead of the close to 3 month period used in this study; and 3) thirdly, in a situation in which PEF monitoring is restricted to those subjects with large fluctuations of PEF and/or frequent exacerbations of asthma and/or "poor sensors" of symptoms. All these situations would warrant separate trials to assess compliance with PEF monitoring.

As expected, compliance tended to decrease with time. Whilst it was close to a mean value of $60 \%$ in the first week, it dropped to $40 \%$ after 1 month, and soon afterwards reached a plateau at approximately $35 \%$. This suggests that even a study with a monitoring period of only 1 or 2 weeks would be hampered by unsatisfactory compliance, although this warrants confirmation in a separate study design in which subjects are asked to record their breathing for only 2 weeks.

When relying on clinical intuition, physicians generally overestimate the degree to which their patients comply with their directives, and often fail to recognize the noncompliant patient [13]. The reason why an asthmatic patient does not adhere to a physician's prescription is complex [14]. The doctor-patient relationship, the patient's interest in and understanding of his/her illness, and the complexity of the prescription may all influence compliance [15]. Asthma is a chronic disease that sometimes shows periods of remission, or even asymptomatic obstruction. It might be compared to diabetes or hypertension, where the problem of perception and reporting of symptoms certainly influences the patient's adherence to medication and to self-surveillance of disease activity. The chronicity of the disease might have a negative impact on adherence. However, in this respect, our study did not demonstrate any significant relationship between compliance and duration or indices of severity of asthma (FEV1, fluctuations in PEF).

Compliance with asthma diaries and PEF monitoring is only one aspect of the general adherence to asthma management $[14,15]$. Comparing asthmatic patients' selfreports of inhaler use with the objective adherence data collected by an electronic medication monitoring device demonstrated that the reports of up to $50 \%$ of patients' might be inaccurate, with the diaries overreporting the actual use of the medication [16]. Other studies have also shown that the compliance evaluation with selfreport or pill-counting overestimates adherence to medication regimen when compared to electronic monitoring of medication usage [17]. In studies which assessed compliance with inhaled steroids, compliance was found to be even poorer than that which we assessed with PEF. Underuse of flunisolide with a prescribed regimen of 8 puffs day $^{-1}$ was found in $69 \%$ of days in the report by MANN et al. [18]. Only 14\% of patients took the correct dose of budesonide morning and evening for more than $80 \%$ of days in the study by BosLey et al. [19].

There is very little information on compliance with PEF monitoring in asthma. REEDER et al. [20] reported on 39 patients who monitored their PEF with two measurements taken in the morning 30 min after awakening over a 3 month period. The study protocol reinforced participation by phone call every 2 weeks. The authors reported that $40 \%$ of their initially recruited subjects had to be dropped from data analysis due to poor adherence to the self-monitoring required for their study. The authors did not have the means, however, to assess compliance blindly as we did in the present study. More recently, JonEs et al. [21] evaluated the validity of PEFbased asthma self-management. Only approximately half of the patients included in the self-management group completed the monitoring over a 6 month period; the authors found no advantages in terms of control of asthma, quality of life and prescribing costs in the group of subjects who assessed their PEF. Compliance with PEF was assessed in two recent studies carried out in subjects suspected of having occupational asthma. Both studies used an electronic device similar to that used in the present study and concluded that compliance and accuracy of reported values were poor $(\sim 50 \%)$; a substantial proportion ( $20 \%$ of values were invented $[8,9]$. These figures are close to the findings of the present study.

In the field of patient psychology, because the acquisition of objective data is difficult to obtain, it is interesting to study single-blindedly patients' behaviour in adhering to a medical recommendation. It was clear to us, both from a clinical and ethical standpoint, that the objective information would not be used against these patients. Nevertheless, this study demonstrates three patterns of compliance into which patients could fit: subjects with variable compliance $(n=7)$; subjects with good 
compliance throughout the study $(n=6)$; and the rapidly poor complier $(n=7)$. It would be interesting to see if these patterns are reproducible or if other patterns could be revealed depending on the type of recommendation asked.

It can be argued that not all asthmatic subjects should record their PEF, and this position has its proponents [21]. We selected subjects who required inhaled steroids to control their asthma. A category of patients for whom PEF monitoring would be justified is those who are "poor sensors" of their symptoms. Up to $60 \%$ of asthmatic subjects treated in general practice were identified as poor discriminators from a visual analogue asthma score scale and simultaneous peak flow measurements [22]. This phenomenon of poor perception is particularly relevant in subjects who may have a predisposition to fatal asthma due to reduced chemosensitivity to hypoxia and blunted perception of dyspnoea [23]. It would be interesting to know whether these subjects would show good compliance.

To summarize, we showed that compliance with peak expiratory flow monitoring is often unsatisfactory in asthmatic subjects using inhaled steroids who are asked to record their values for a 3 month period in order to provide information to the physician on the severity of asthma. In this situation, a substantial number of values were invented and it is unlikely that peak expiratory flow monitoring would represent a satisfactory means for monitoring asthma on a chronic basis, such as in clinical or drug trials. Compliance with peak expiratory flow monitoring would also need to be assessed in other circumstances: 1) as used in an action plan; 2) on an asneeded basis, i.e. only if subjects feel their symptoms increase; and 3) in more severe and brittle asthmatics.

Acknowledgements: The authors would like to thank L. Schubert for reviewing the manuscript.

\section{References}

1. American Thoracic Society. Chronic bronchitis, asthma, and pulmonary emphysema. Statement by the committee on diagnostic standards for nontuberculous respiratory diseases. Am Rev Respir Dis 1962; 85: 762-768.

2. Shim CS, Williams MH. Evaluation of the severity of asthma: patients versus physicians. Am J Med 1980; 68: $11-13$.

3. Rubinfeld AR, Pain MCF. Perception of asthma. Lancet 1976; 882-884.

4. Burki NK, Mitchell K, Chaudhary BA, Zechman FW. The ability of asthmatics to detect added resistive loads. Am Rev Respir Dis 1978; 117: 71-75.

5. Boulet LP, Leblanc P, Turcotte H. Perception scoring of induced bronchoconstriction as an index of awareness of asthma symptoms. Chest 1994; 105: 1430-1433.

6. Woolcock A, Rubinfeld AR, Seale JP, et al. Asthma management plan, 1989. Med J Aust 1989; 151: 650-653.
7. Hargreave FE, Dolovich J, Newhouse MT. The assessment and treatment of asthma: a conference report. $J$ Allergy Clin Immunol 1990; 85: 1098-1111.

8. Malo JL, Trudeau C, Ghezzo H, L'Archevêque J, Cartier A. Do subjects investigated for occupational asthma through serial PEF measurements falsify their results? J Allergy Clin Immunol 1995; 96: 601-607.

9. Quirce S, Contreras G, DyBuncio A, Chan-Yeung M. Peak expiratory flow monitoring is not a reliable method for establishing the diagnosis of occupational asthma. Am J Respir Crit Care Med 1995; 152: 1100-1102.

10. American Thoracic Society. Standardization of spirometry. Am J Respir Care Med 1995; 152: 1107-1136.

11. Knudson RJ, Lebowitz MD, Holberg CJ, Burrows B. Changes in the normal maximal expiratory flow-volume curve with growth an aging. Am Rev Respir Dis 1983; 127: 725-734.

12. Burge PS, O'Brien IM, Harries MG. Peak flow rate records in the diagnosis of occupational asthma due to isocyanates. Thorax 1979; 34: 317-323.

13. Mushlin AI, Appel FA. Diagnosing potential noncompliance. Arch Intern Med 1977; 137: 318-321.

14. Rand CS, Wise RA. Measuring adherence to asthma medication regimens. Am J Respir Crit Care Med 1995; 149: 569-576.

15. Masur FT. Adherence to health care regimens. In: Prokop CK, Bradley LA, eds. Medical Psychology: Contributions to Behavioural Medicine. New York, Academic Press Inc., 1981; pp. 441-470.

16. Spector SL, Kinsman R, Mawhinney H, et al. Compliance of patients with asthma with an experimental aerosolized medication: implications for controlled clinical trials. J Allergy Clin Immunol 1986; 77: 65-70.

17. Spilker B. Methods of assessing and improving patient compliance in clinical trials. In: Cramer JA, Spilker B, eds. Patient Compliance in Medical Practice and Clinical Trials. New York, Raven Press Ltd, 1991; pp. 37-56.

18. Mann M, Eliasson O, Patel K, ZuWallack RL. A comparison of the effects of b.i.d. and q.i.d. dosing on compliance with inhaled flunisolide. Chest 1992; 101: 496-499.

19. Bosley CM, Parry DT, Cochcrane GM. Patient compliance with inhaled medication: does combining betaagonists with corticosteroids improve compliance? Eur Respir J 1994; 7: 504-509.

20. Reeder KP, Dolce JJ, Duke L, Raczinski JM, Bailey WC. Peak flow meters: are they monitoring tools or training devices? J Asthma 1990; 27: 219-227.

21. Jones KP, Mulleee MA, Middleton M, Chapman E, Holgate ST and the British Thoracic Society Research Committee. Peak flow based asthma self-management: a randomised controlled study in general practice. Thorax 1995; 50: 851-857.

22. Kendrick AH, Higgs CMB, Whitfield MJ, Lazlo G. Accuracy of perception of severity of asthma: patients treated in general practice. BMJ 1993; 307: 422-424.

23. Kikuchi Y, Okabe S, Tamura G, et al. Chemosensitivity and perception of dyspnoea in patients with a history of near-fatal asthma. N Engl J Med 1994; 330: 1329_ 1334. 